\title{
Bu open Young adult women smokers' response to using plain cigarette packaging: a naturalistic approach
}

To cite: Moodie CS, Mackintosh AM. Young adult women smokers' response to using plain cigarette packaging: a naturalistic approach. BMJ Open 2013;3:e002402. doi:10.1136/bmjopen-2012002402

- Prepublication history and additional material for this paper are available online. To view these files please visit the journal online (http://dx.doi.org/10.1136/ bmjopen-2012-002402).

Received 25 November 2012 Revised 21 February 2013 Accepted 25 February 2013

This final article is available for use under the terms of the Creative Commons Attribution Non-Commercial 2.0 Licence; see http://bmjopen.bmj.com

Centre for Tobacco Control Research, Institute for Social Marketing, University of Stirling, Stirling, Scotland

Correspondence to Dr Crawford Moodie; c.s.moodie@stir.ac.uk

\section{ABSTRACT}

Objectives: To explore young adult women smokers cognitive and emotional response to using dark brown 'plain' cigarette packs in natural settings and whether plain packaging is associated with any short-term change in smoking behaviour.

Design: A naturalistic approach. Participants used plain cigarette packs provided to them for 1 week and for 1 week their own fully branded packs, but otherwise smoked and socialised as normal. Participants completed questionnaires twice a week.

Setting: The six most populated cities and towns in Scotland.

Participants: 301 young women smokers were recruited, with a final sample of $187(62.1 \%)$. To meet the inclusion criteria women had to be between the ages of 18 and 35 , daily cigarette smokers and provide a breath sample to confirm smoking status.

Primary and secondary outcome measures:

Pack perceptions and feelings, feelings about smoking, salience and perceptions of health warnings and avoidant and cessation behaviours.

Results: In comparison to fully branded packaging, plain packaging was associated with more negative perceptions and feelings about the pack and about smoking $(p<0.001)$. No significant overall differences in salience, seriousness or believability of health warnings were found between the pack types, but participants reported looking more closely at the warnings on plain packs and also thinking more about what the warnings were telling them $(p<0.001)$. Participants reported being more likely to engage in avoidant behaviours, such as hiding or covering the pack $(p<0.001)$, and cessation behaviours, such as foregoing cigarettes $(p<0.05)$, smoking less around others $(p<0.001)$, thinking about quitting $(p<0.001)$ and reduced consumption $(p<0.05)$, while using the plain packs. Results did not differ by dependence level or socioeconomic status.

Conclusions: No research design can capture the true impacts of plain packaging prior to its introduction, but this study suggests that plain packaging may help reduce cigarette consumption and encourage cessation in the short term.

\section{ARTICLE SUMMARY}

Article focus

- How young adult women smokers respond to using plain cigarette packaging, in comparison with fully branded cigarette packaging. We explored the impact of plain packaging on shortterm smoking-related behaviour.

Key messages

- Plain packaging was associated with lower ratings of enjoyment and satisfaction of smoking in comparison with fully branded packaging.

- Participants reported looking more closely at the health warnings on plain packs and also thinking more about what the warnings were telling them.

- Plain packaging, in comparison with fully branded packaging, was associated with foregoing cigarettes, smoking less around others, increased thoughts of cessation and reduced consumption.

Strengths and limitations of this study

- The main strength of the study is that it allows an insight into how smokers respond to plain packaging before it has been introduced.

- The main limitations are the novelty of plain packaging and reliance on self-reported smoking behaviour.

\section{INTRODUCTION}

At the annual meeting of the Canadian Medical Association in 1986 it was proposed that all tobacco products should come in 'plain' brown standardised packs in order to minimise their attractiveness. ${ }^{1}$ Approximately a quarter of a century on and plain tobacco packaging was fully implemented in Australia, for the first time, in December 2012. Prior to this, consultations on plain packaging ended in New Zealand in October and in the UK in August 2012. What the actual impacts of plain packaging will be, if any, remain to be seen however. A recent systematic review of the plain packaging literature, with 37 included studies, suggests that plain packaging may have a number of potential public health benefits, including: (1) reducing the appeal of 
the packaging and of cigarettes, (2) increasing the salience, believability and seriousness of the health warnings, although this was influenced by the type (pictorial or text), size and strength of the warnings used and (3) increasing perceptions of harm, although this was dependent upon the colour of the plain pack, with darker-coloured plain packs typically perceived as more harmful, and lighter-coloured plain packs less harmful, than fully branded cigarette packs. ${ }^{2}$

One of the longstanding criticisms of the literature is that existing research typically involves gauging consumer response to plain packaging following brief exposure in a controlled environment and, as a result, fails to capture how consumers would react to and use plain packs over time in naturalistic settings. To date only one study has attempted a real-world test of plain packaging. This study used a design which involved young adult men and women smokers in Glasgow (Scotland) transferring cigarettes from their own packs into brown (plain) packs provided and using these packs instead of their own packs for 2 weeks, and their own packs for 2 weeks. ${ }^{3}$ Participants completed a questionnaire twice a week throughout the study to allow for comparisons to be made between the plain packs and their own packs. Pack perceptions and feelings, and feelings about smoking, were more negative for plain packs and participants were more likely to report avoidant behaviours (eg, covering the pack) and cessation-related behaviours (eg, thinking about quitting) while using the plain packs. Poststudy interviews were conducted with a subsample of participants $(\mathrm{N}=18)$ to explore their experiences of using the brown (plain) packs. In the poststudy interviews women were more likely than men to report avoidant behaviour while using the plain packs, and only women reported reduced consumption when using plain packs. The pilot nature of this study, recruitment within a single city, low retention rate $(34 \%)$ and relatively small final sample $(\mathrm{N}=48)$ means that further research is needed to test these findings.

We aimed to extend this previous study by following the same approach but with a larger and more nationally distributed sample of young adult women smokers, who appeared to be more influenced by pack design than men in the pilot study. While high rates of smoking among women tend to be the norm in most of Europe, with a prevalence of $20 \%$ or more in all but four European Union member countries (Italy, Portugal, Slovakia and Sweden), this contrasts sharply with much of the rest of the world. ${ }^{4}$ Prevalence of smoking among women is less than $20 \%$ in the Middle East, North and Central America and Asia (excluding Lebanon and Nepal), and less than $10 \%$ in Africa, where figures are available. ${ }^{4}$ In the UK smoking prevalence among women is currently $20 \%$ and in long-term decline, but prevalence is declining at a slower rate than it is for men and remains particularly high for young adult women, with $25 \%$ of 25-year-old to 34-year-old women and $30 \%$ of 20-year-old to 24-year-old women smokers. ${ }^{5}$
The high smoking rates among young women in the UK represents a significant future burden of both mortality and morbidity should this trend not be reversed. With a growing number of slim, elegant cigarette packs targeted at young women being brought to the market in the UK and elsewhere within the last 5 years, and given that the aesthetic appeal of cigarette packaging appears to be more important for young women than for young men, ${ }^{36-8}$ plain packaging may have a role to play in reducing the high rates of smoking among young women. This study explored young women's experiences of using plain cigarette packaging as they went about their everyday lives.

\section{METHODS}

\section{Design and sample}

Between June 2011 and March 2012 young adult women smokers $(\mathrm{N}=301)$ were recruited from eight postcode sectors from within the six most populated towns and cities in Scotland (Glasgow, Edinburgh, Aberdeen, Dundee, Paisley and East Kilbride) using random location quota sampling. The postcode sectors were randomly selected, stratified by DEPCAT score, which is a measure of multiple deprivation, to ensure coverage of a range of socioeconomic backgrounds. Within each postcode sector, market recruiters were instructed to recruit either six or seven participants, using the door knock method, according to quota controls on age (18-24/25-35) and daily consumption (light/moderate smokers were defined as those smoking 14 cigarettes a day or less, heavy smokers as those smoking 15 cigarettes a day or more).

The market recruiters, who were briefed about the study protocol but blind to the purpose of the study, informed all potential participants that the study was concerned with smokers' opinions of cigarette packaging. If individuals were willing to participate and available for the duration of the study, they were asked to complete a recruitment questionnaire, which included the Fagerström Test for Nicotine Dependence ${ }^{9}$ and questions regarding brand variant smoked, risk perceptions and cessation behaviour (eg, motivation to quit and attempts to quit). To ensure only smokers were recruited, participants were asked to provide a breath sample using a piCO $^{+}$Carbon Monoxide monitor (Bedfont Scientific, Kent, England) and also an empty cigarette pack; in the four instances where a participant only had a full pack, recruiters took a photo of their pack and texted this to a member of the research team. Ethics approval was obtained from the ethics committee of the Marketing Department at the University of Stirling. Participants provided informed consent before participating.

\section{Materials and procedure}

Participants were informed about the study protocol by market recruiters and, if they gave consent, were provided with a 'completion' pack. Each completion pack included seven brown (plain) cigarette packs. These 
brown packs were only suitable for participants who smoked King Size cigarettes, as was the case in a pilot study using the same approach. ${ }^{3}$ As 9 of the top 10 selling cigarette brand variants in the UK come in King Size packs most smokers would have been eligible for study inclusion. However, as all of the top 25 selling cigarette brand variants in the UK come in either King Size or Superkings packs, ${ }^{10}$ which are slightly bigger than the standard King Size pack, market recruiters were given a box of Superkings plain packs and instructed to use these where appropriate. This involved replacing the seven King Size brown packs within the completion pack with seven Superkings brown packs if an individual smoked a Superkings brand or other longer cigarettes, such as Slims or Superslims. The plain packs were otherwise identical, with a fictitious brand name Kerrods, to prevent copyright breach, and all relevant legal markings and a barcode. The completion packs also included five numbered questionnaires, labelled by day and date, and a timetable explaining when to use their own packs and the Kerrods packs and when to complete and return each of the five questionnaires.

The study, which always started on a Monday, ran for 2 weeks. Participants were instructed to transfer cigarettes from their own packs into the Kerrods packs supplied to them and use these for 1 week of the study, and their own packs for the other week of the study. Ordering was randomised so that half the sample used the plain pack in the first week of the study and half in the second week. Participants were instructed to retain and reuse the Kerrods packs if they smoked more than 20 cigarettes in a day. In the UK cigarette packs contain 1 of 2 text health warnings on the front ('Smoking kills' or 'Smoking seriously harms you and others around you') and 1 of 14 'pictorial' warnings on the reverse panel, although 3 are in fact text warnings as they do not display a picture, photo, pictogram or symbol. All Kerrods packs had the same warning on the pack front (smoking kills) and one of three 'pictorial' warnings on the reverse panel showing either a set of healthy and diseased lungs, smoke in a child's face or a text warning about seeking help (see figure 1). Past research has found these three warnings to have high (lungs), medium (smoke in child's face) and low salience (seeking help) among smokers. ${ }^{11}$ Each completion pack contained at least two packs with each of the three warnings. We included packs with different health warnings to reflect the types of warnings that smokers receive on packs and prevent all packs featuring only warnings found to have high or low salience, as this could potentially influence response to the warning items.

Participants were instructed to complete five questionnaires during the 2 weeks of the study. Questionnaires 1 and 2 were to be completed and returned, via preaddressed envelopes or by email, on Thursday and Sunday, respectively, of the first week. Questionnaires 3 and 4 were to be completed and returned on the Thursday and Sunday, respectively, of the second week. The first four questionnaires, which were identical (see Appendix 1), resulted in two questionnaires relating to their experience with the plain packs and two with their own packs. Questionnaire 5 included the same questions as the prestudy questionnaire about risk perceptions and cessation behaviour, and was to be completed and returned on the same day as questionnaire 4 to reduce participant burden. This is not included in this analysis.

Although the day and date each questionnaire was to be completed and returned was highlighted on the front cover and specified in the timetable, in an attempt to increase study compliance the research team sent a text message to each participant the day before the onset of the study, always a Sunday. The text reminded participants: (1) that the study would start the next day, (2) what packs they were to use for the coming week and (3) to complete questionnaire 1 the following Thursday (the day and date were given for clarity). A second text message was sent the following Sunday to remind participants to complete and return questionnaire 2 that day, and which packs to use for the following week. A third and final text was sent the subsequent Sunday, reminding participants to complete and return questionnaires 4 and 5 that day. Participants were also sent a reminder letter during the first week of the study and an email was sent every Thursday and Sunday morning to participants who had provided an email address as an additional reminder to complete and return the questionnaires. To encourage the return of all the questionnaires participants were informed that on top of the participation fee $(£ 15.00)$ they would receive an incrementally greater payment for each questionnaire returned; $£ 2.50$ if they returned one questionnaire, $£ 7.00$ if they returned two questionnaires, $£ 12.00$
Figure 1 Brown 'plain' packs and health warnings used on the front and back of packs.

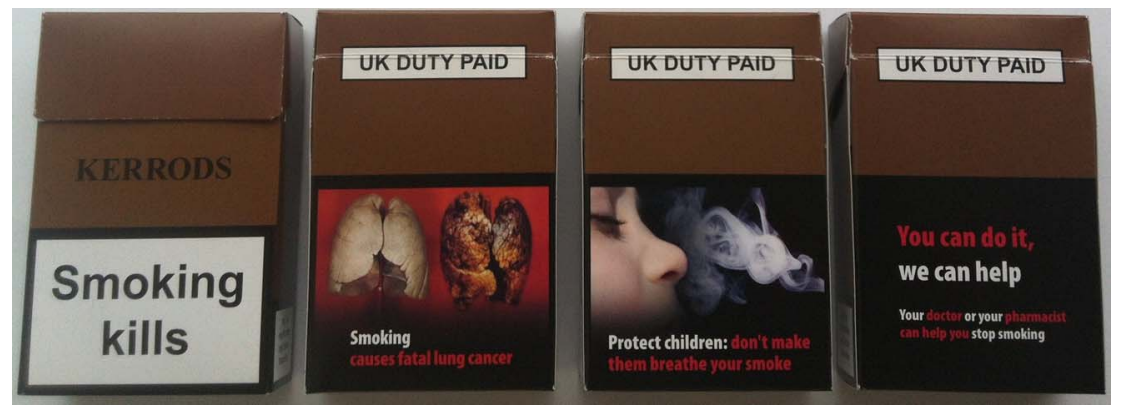


for three, £20.00 for four and $£ 30.00$ for all five. Participants were provided with an information sheet to remind them of this incremental payment plan.

\section{Analysis}

Prior to analysis, some items were recoded to ensure the same direction of coding and thus facilitate creation and interpretation of composite variables. Composite scores were derived for pack perceptions, pack feelings, feelings about smoking and response to warnings, by summing the individual items within each and then rescaling to a five-point scale. Cronbach's $\alpha$ was acceptable for each, all above 0.70 with the exception of the overall health warning response for own pack which had an $\alpha$ of 0.65 , thus supporting the decision to create composite scores for each measure and for each pack type.

Ratings between fully branded and Kerrods plain packs were compared. Ratings collected from the Thursday questionnaires are referred to as 'midweek' and those collected from the following Sunday questionnaires referred to as 'weekend'. For each analysis, midweek ratings of the Kerrods pack were compared with midweek ratings of their own pack and weekend ratings of the Kerrods pack were compared with weekend ratings of their own pack. Paired $t$ tests were used to produce mean scores for the Kerrods pack relative to mean scores for their own pack. Given the ordinal nature of the five-point scales, the Wilcoxon Signed Rank test was used to test for differences between ratings of the Kerrods pack versus participant's own packs. As the data on avoidant/cessation behaviours were binary (yes/no) the McNemar test was used to test for differences in response to the Kerrods pack versus their own pack. The number of avoidant/cessation behaviours associated with each pack was also counted and paired $t$ tests were used to test for differences in the mean number of actions taken with the Kerrods pack versus their own pack. Similarly, paired t tests were used to test for differences in mean reported daily consumption while using the Kerrods pack versus their own pack. Comparisons across time were also made by comparing the midweek composite scores versus the weekend composite scores for the Kerrods pack and comparing the midweek composite scores versus the weekend composite scores for their own pack. The Wilcoxon Signed Rank test was used to test for differences, across time, in the composite scores. Paired t tests were used to test for differences between midweek and weekend reports on the number of avoidant/cessation behaviours and reported daily consumption with each pack.

Given the paucity of plain packaging research exploring subgroup differences, ${ }^{2}$ analyses of the composite scores were also run separately to explore whether the results were consistent with age group (18-24, 25-35), social grade (ABC1, C2DE) and dependence level (light, moderate/high). Social grade, based on occupation, was classified in accordance with the six groups (A, upper middle class; B, middle class; C1, lower middle class; C2, skilled working class; D, working class and $\mathrm{E}$, those at the lowest level of subsistence) used by the British National Readership Survey. These six groups were combined to form two groups to enable broad comparison between middle-class (ABC1) and working-class (C2DE) participants. Dependence level was measured via the Fagerström Test for Nicotine Dependence, ${ }^{9}$ with those scoring between 0 and 5 categorised as having light/moderate dependence and those scoring 6-10 high dependence levels.

\section{RESULTS}

Of the 301 participants recruited, 54 (17.9\%) were noncompleters, who failed to participate at all after completing the prestudy questionnaire, $60(19.9 \%)$ were partial completers, who failed to return all the questionnaires or reported using the incorrect pack (eg, they used their own packs when they were meant to be using the Kerrods packs), and 187 (62.1\%) were full completers, who returned all the questionnaires and reported using the correct packs. Results presented in this paper are based on the full completers. The average age of the full completers was 27.14 years (SD 5.63); 84 (44.9\%) were from social grade $\mathrm{ABC} 1$ and $103(55.1 \%)$ from social grade C2DE; $96(51.3 \%)$ had light/moderate dependence and 91 (48.7\%) high dependence; average daily cigarette consumption was 17.28 (SD 7.19); 33 (17.6\%) had given up for 1 day or more in the previous month and $129(69 \%)$ indicated that they would like to or really wanted to give up smoking. There was no significant difference in terms of age, dependence level or motivation to quit between those included in the analyses and those excluded (non-completers and partial completers). However, participants from social group $\mathrm{ABC1}$ were more likely to complete the study $(71.2 \%$ of ABC1s were full completers vs $56.6 \%$ of C2DEs, $\mathrm{p}<0.05$ ) as were participants with a past-month quit attempt of 1 day or more $(78.6 \%$ of those with a past-month quit attempt completed the study vs $59.7 \%$ of those with no past-month quit attempt, $\mathrm{p}<0.05$ ).

\section{Pack perceptions}

On average, participants rated Kerrods negatively on all pack perceptions (not stylish, unfashionable, cheap, uncool, unattractive, poor quality, unappealing), with mean scores ranging from 1.55 to 2.37; lower scores indicating more negative perceptions (see table 1A). For their own packs the higher mean scores, ranging from 2.91 to 3.69 , indicated more positive pack perceptions. For the overall pack perception score (all items combined), participants rated the Kerrods pack more negatively than their own pack, and this did not vary across time for either pack. Results were consistent with age group, social grade and dependence level.

\section{Pack feelings}

On average, participants reported more negative feelings (embarrassed, ashamed, unaccepted) about using the Kerrods pack, relative to their own pack (see table 1B). 
Table 1 Mean ratings on response to Kerrods pack versus own pack for pack perceptions, pack feelings and feelings about smoking

\begin{tabular}{|c|c|c|c|c|}
\hline & \multicolumn{2}{|l|}{ Midweek } & \multicolumn{2}{|l|}{ Weekend } \\
\hline & \multirow{2}{*}{\multicolumn{2}{|c|}{$\begin{array}{l}\text { Mean } \\
S n\end{array}$}} & \multicolumn{2}{|l|}{ Mean } \\
\hline & & & $\overline{S D}$ & \\
\hline & Kerrods & Own & Kerrods & Own \\
\hline \multicolumn{5}{|l|}{ (A) Pack perceptions (7 items) } \\
\hline Style & 1.55 & $3.16^{\star * *}$ & 1.62 & $3.23^{\star \star \star}$ \\
\hline Not stylish(1)/stylish(5) & 0.88 & 0.99 & 0.90 & 0.98 \\
\hline Fashion & 2.30 & $3.07^{\star \star \star}$ & 1.88 & $3.08^{\star \star \star}$ \\
\hline Unfashionable(1)/fashionable(5) & 1.53 & 1.03 & 1.22 & 1.02 \\
\hline Cheap & 1.74 & $3.30^{\star \star *}$ & 1.90 & $3.37^{\star \star *}$ \\
\hline Cheap(1)/expensive(5) & 0.99 & 1.08 & 1.02 & 1.03 \\
\hline Cool & 1.74 & $2.95^{\star \star \star}$ & 1.76 & $2.91^{\star \star \star}$ \\
\hline Uncool(1)/cool(5) & 0.87 & 0.99 & 0.89 & 0.94 \\
\hline Attractive & 1.78 & $3.03^{\star \star *}$ & 1.72 & $3.07^{\star \star \star}$ \\
\hline Unattractive(1)/attractive(5) & 1.15 & 1.14 & 0.99 & 1.05 \\
\hline Quality & 2.37 & $3.69^{\star \star \star}$ & 2.26 & $3.64^{\star * *}$ \\
\hline Poor quality(1)/good quality(5) & 1.16 & 0.95 & 1.11 & 0.93 \\
\hline Appealing & 1.81 & $3.19^{\star \star \star}$ & 1.85 & $3.16^{\star * *}$ \\
\hline Unappealing(1)/appealing(5) & 1.06 & 1.08 & 1.04 & 0.97 \\
\hline \multicolumn{5}{|l|}{ Overall pack perceptions } \\
\hline Composite score & 1.90 & $3.19^{\star * \star}$ & 1.85 & $3.21^{\star \star \star}$ \\
\hline Low score=negative perceptions/high score=positive perceptions & 0.72 & 0.07 & 0.73 & 0.76 \\
\hline \multicolumn{5}{|l|}{ (B) Pack feelings (3 items) } \\
\hline Embarrassment & 2.70 & $4.08^{\star * *}$ & 2.54 & $3.84^{\star \star *}$ \\
\hline Embarrassed(1)/not embarrassed(5) & 1.29 & 1.14 & 1.25 & 1.04 \\
\hline Ashamed & 3.10 & $4.02^{\star \star \star}$ & 2.71 & $3.72^{\star \star \star}$ \\
\hline Ashamed(1)/not ashamed(5) & 1.26 & 1.12 & 1.18 & 1.08 \\
\hline Acceptance & 2.69 & $3.37^{\star \star \star}$ & 2.55 & $3.26^{\star \star \star}$ \\
\hline Unaccepted(1)/accepted(5) & 1.02 & 1.07 & 0.95 & 0.99 \\
\hline \multicolumn{5}{|l|}{ Overall pack feelings } \\
\hline Composite score & 2.84 & $3.82^{\star * \star}$ & 2.60 & $3.62^{\star \star *}$ \\
\hline Low score=negative perceptions/high score=positive perceptions & 1.03 & 0.92 & 0.99 & 0.86 \\
\hline \multicolumn{5}{|l|}{ (C) Feelings about smoking ( 3 items) } \\
\hline Enjoyment & 2.90 & $3.40^{\star * \star}$ & 2.73 & $3.40^{\star \star \star}$ \\
\hline Enjoyable(1)/ enjoyable(5) & 0.97 & 0.95 & 0.97 & 0.96 \\
\hline Satisfaction & 2.99 & $3.52^{\star \star \star}$ & 2.83 & $3.41^{\star * *}$ \\
\hline Not satisfying(1)/satisfying(5) & 0.99 & 0.93 & 1.00 & 0.98 \\
\hline Good & 2.73 & $3.13^{\star \star \star}$ & 2.68 & $3.19^{\star * *}$ \\
\hline $\operatorname{Bad}(1) / \operatorname{good}(5)$ & 0.87 & 0.93 & 0.95 & 0.98 \\
\hline \multicolumn{5}{|l|}{ Overall feelings smoking } \\
\hline Composite score & 2.88 & $3.36^{\star \star \star}$ & 2.75 & $3.34^{\star \star \star}$ \\
\hline Low score=negative perceptions/high score=positive perceptions & 0.82 & 0.83 & 0.89 & 0.87 \\
\hline
\end{tabular}

For the Kerrods pack, mean scores ranged from 2.54 to 3.10 , whereas mean scores for their own pack ranged from 3.26 to 4.08 . For both their own packs and the Kerrods pack, overall pack feelings were rated more negatively during the weekend compared with midweek $(\mathrm{p}<0.001)$. Results were consistent by age group, social grade and dependence level.
Feelings about smoking

Participants reported more negative feelings about smoking from the Kerrods pack, in terms of enjoyment, satisfaction and feeling good, relative to their own pack (see table 1C). For the Kerrods pack, mean scores ranged from 2.68 to 2.99 , while mean scores for their own packs ranged from 3.13 to 3.52. Overall ratings for 
their own packs did not vary across time. For the Kerrods pack, overall feelings about smoking were rated more negatively during the weekend compared with midweek $(p<0.05)$. Results were consistent across age group, social grade and dependence level.

\section{Health warnings}

Salience, seriousness and believability

For both pack types, the on-pack health warnings were rated as being noticeable (mean scores 3.41-3.44), serious (3.83-3.94) and believable (3.91-4.10), see table 2. During the weekend only, warnings on the Kerrods pack were rated as more believable relative to participants' own packs. However, overall ratings of the warnings did not differ between the packs, and did not vary across time for either pack. Findings were consistent across age, social grade and dependence level.

\section{Attention and depth of processing}

Warnings were rated as being read more closely on the Kerrods pack (mean scores 2.97-3.00) than on their own packs (mean scores 2.28-2.58), and thought about more on the Kerrods pack (mean scores 3.02-3.16) relative to participants' own packs (mean scores 2.52-2.80). The overall results were consistent for the age and dependence level subgroups. However, during the weekend, participants from social grade C2DE did not show any significant difference between Kerrods and own pack, in overall warning action response. While there was no difference in the overall Kerrods ratings across time, the own pack ratings were stronger during the weekend compared with midweek $(\mathrm{p}<0.001)$.

\section{Avoidant behaviour/behaviour change}

Participants always indicated greater occurrence of the following actions when using the Kerrods packs: keeping the pack out of sight; covering the pack; foregoing cigarettes; smoking less around others; thinking about quitting (table 3). In addition, when using the Kerrods pack, participants were more likely to stub out a cigarette, although only significantly so during the weekend. They were also more likely to want to quit smoking, when using the Kerrods pack, though only significantly so at midweek. On average, participants reported a higher number of behaviour changes or avoidant behaviours when using the Kerrods pack (1.88 and 2.29 midweek and weekend, respectively) compared with their own pack (0.84 and 1.12 midweek and weekend, respectively). This result was consistent with age, social grade and dependence level. For each pack type, the number of behaviour changes/avoidant behaviours increased during the weekend $(\mathrm{p}<0.001$ for Kerrods and $\mathrm{p}<0.01$ for own pack).

Reported consumption was always lower with the Kerrods pack compared with participants' own pack. Midweek average daily consumption was 14.9 while using

Table 2 Mean ratings on response to Kerrods pack versus own pack for health warning salience and credibility, and attention and depth of processing

\begin{tabular}{|c|c|c|c|c|}
\hline & \multicolumn{2}{|l|}{ Midweek } & \multicolumn{2}{|l|}{ Weekend } \\
\hline & \multicolumn{2}{|l|}{ Mean } & \multicolumn{2}{|l|}{ Mean } \\
\hline & \multicolumn{2}{|l|}{$\overline{S D}$} & \multicolumn{2}{|l|}{$S D$} \\
\hline & Kerrods & Own & Kerrods & Own \\
\hline \multicolumn{5}{|l|}{ Health warnings (salience and credibility) } \\
\hline Noticing & 3.44 & 3.43 & 3.41 & 3.25 \\
\hline Hardly noticeable(1)/very (5) & 1.39 & 1.33 & 1.40 & 1.29 \\
\hline Seriousness & 3.94 & 3.83 & 3.84 & 3.89 \\
\hline Not serious(1)/serious (5) & 1.12 & 1.12 & 1.26 & 1.04 \\
\hline Believability & 4.10 & 4.08 & 4.09 & $3.91^{*}$ \\
\hline Not believable(1)/believable (5) & 1.09 & 0.98 & 1.09 & 1.06 \\
\hline \multicolumn{5}{|l|}{ Overall warning response } \\
\hline Composite score & 3.92 & 3.77 & 3.77 & 3.67 \\
\hline Low score=little, no impact/high score=high impact & 0.97 & 0.93 & 1.01 & 0.88 \\
\hline \multicolumn{5}{|l|}{ Health warnings (attention and depth of processing) } \\
\hline Attention & 3.00 & $2.28^{\star \star \star}$ & 2.97 & $2.58^{\star * *}$ \\
\hline Not looking closely(1)/looking closely (5) & 1.47 & 1.34 & 1.51 & 1.35 \\
\hline Thinking about warnings & 3.02 & $2.52^{\star \star \star}$ & 3.16 & $2.80^{\star * *}$ \\
\hline $\begin{array}{l}\text { Not think about what they are telling you(1)/thinking about what they } \\
\text { are telling you (5) }\end{array}$ & 1.41 & 1.36 & 1.47 & 1.34 \\
\hline \multicolumn{5}{|l|}{ Overall warning action response } \\
\hline Composite score & 3.00 & $2.39^{\star \star \star}$ & 3.06 & $2.69^{\star * *}$ \\
\hline Low score=little or no action/high score=high action & 1.38 & 1.26 & 1.42 & 1.27 \\
\hline
\end{tabular}


Table 3 Proportion of participants reporting avoidant behaviour or behaviour change as a result of the pack

\begin{tabular}{|c|c|c|c|c|}
\hline \multirow[b]{2}{*}{ Behaviour change/avoidant behaviour } & \multicolumn{2}{|c|}{ Midweek (\%) } & \multicolumn{2}{|l|}{ Weekend } \\
\hline & Kerrods & Own & Kerrods & Own \\
\hline Stub out cigarette & 10 & 5 & 17 & $10^{*}$ \\
\hline Forego a cigarette & 13 & $4^{\star *}$ & 15 & $8^{*}$ \\
\hline Keep pack out of sight & 54 & $11^{\star * *}$ & 55 & $10^{\star * \star}$ \\
\hline Cover pack & 10 & $2^{\star \star \star}$ & 21 & $3^{\star \star \star}$ \\
\hline Smoke less around others & 33 & $11^{\star \star \star}$ & 39 & $16^{\star \star \star}$ \\
\hline Think about quitting & 39 & $26^{\star \star \star}$ & 46 & $34^{\star * *}$ \\
\hline Want to quit & 33 & $25^{\star}$ & 37 & 32 \\
\hline Mean number of actions & 1.88 & $0.84^{\star * \star}$ & 2.29 & $1.12^{\star \star \star}$ \\
\hline$S D$ & 1.80 & 1.36 & 2.16 & 1.61 \\
\hline
\end{tabular}

Kerrods and 15.5 while using their own pack $(\mathrm{p}<0.05)$, with weekend average daily consumption 15.7 while using Kerrods and 16.7 while using their own pack $(p<0.01)$. The pattern of lower consumption, while using the Kerrods pack versus their own pack, was observed within each of the age, social grade and dependence level subgroups, but did not always reach significance. Consumption was higher at the weekend for each pack ( $p<0.05$ for Kerrods and $p<0.01$ for own pack).

\section{DISCUSSION}

For young adult women smokers, a key target group for public health, the use of dark brown (plain) cigarette packs in naturalistic settings was associated with more negative perceptions and feelings about the packaging and about smoking than for their own fully branded packs. As with past research in the UK the base colour of the plain packs, a faecal brown, was perceived negatively. ${ }^{3} 1213$ Plain packs were also associated with more negative feelings about the pack, in terms of embarrassment and shame, lower ratings of enjoyment and satisfaction of smoking, and increased avoidant (hiding and covering the pack) and cessation-related smoking behaviours (stubbing out cigarettes early, foregoing cigarettes and reduced consumption). These findings closely reflect those of a pilot study using the same approach. ${ }^{3}$ The key differences to emerge between the studies were that in the pilot study stubbing out cigarettes early while using the plain packs was never significant and foregoing cigarettes while using plain packs was not always significant. As the level of consumption was not measured in the pilot study questionnaires no comparisons can be made.

\section{Study strengths}

The study permits an insight into how smokers respond to plain packaging in natural settings before it has been introduced. It is difficult to envisage an alternative approach which would allow smoking-related behaviours to be captured, such as stubbing out cigarettes early, foregoing cigarettes and reduced consumption. Similarly, as the study did not involve forced exposure to packaging it more accurately reflects how smokers respond to the on-pack health warnings, with respect to the attention they are given, how they are perceived and also how deeply they are processed. There were no significant overall differences among ratings of warning salience, seriousness and believability, consistent with a pilot naturalistic study and two recent eye-tracking studies from the UK. ${ }^{3} 14{ }^{15}$ Warning design may, in part, help explain these findings. The positioning of images only on the reverse panel of packaging is inconsistent with the Guidelines for Article 11 of the Framework Convention on Tobacco Control ${ }^{16}$ and best international practice. Indeed, very few countries outside of Europe that require pictorial warnings to be displayed on cigarette packs, such as Argentina and Venezuela, fail to use pictorial warnings on the pack front. Including pictorial warnings only on the reverse panel of packaging has been found to reduce warning effectiveness. ${ }^{9}$ Similarly, lack of rotation is likely to have increased wear-out; although images appeared on the reverse panel of packs in the UK in 2008 to support the warning text, the text has been on packs since 2003. Warnings on plain packs were read more closely and thought about more than those on branded packs however. That warnings on plain packs were attended to more closely and more deeply processed, which was not assessed in the pilot study, advances our understanding of the possible realworld impacts of plain packaging.

It is not only cessation-related behaviours such as stubbing out or foregoing cigarettes which can be captured with such an approach, but also behaviours such as smoking less around other people. The UK Department of Health speculate that a potential benefit of plain packaging could be to reduce exposure to second-hand smoke (SHS) from reduced rates of smoking, ${ }^{17}$ which would reduce the high annual direct costs to the National Health Service incurred by treating illness related to exposure to SHS. ${ }^{18}$ That young women reported smoking less around others while using the plain packs suggests that the 
appearance of the pack, and how it makes some young women feel and think about smoking, may in itself lead to lower exposure to SHS. The Department of Health also suggested that future research consider consumer response to plain packaging across socioeconomic groups ${ }^{17}$ which is somewhat surprisingly lacking in the existing literature. ${ }^{2}$ We found no significant differences across income groups, or indeed by age or dependence levels. While this suggests that plain packaging could potentially help benefit all young women, caution should be exercised as the sample size did not permit a more detailed breakdown of socioeconomic status or dependence.

\section{Limitations}

The study has a number of limitations. The reliance on self-reporting, both in terms of reported behaviour change and the use of the Kerrods packs, is a potential limitation. Given the high level of participant involvement and the nature of the research it is difficult to see a viable alternative. One way would have been to provide participants with their brand of cigarettes already within the plain packs, which would eliminate the need for cigarettes to be transferred from one pack into another, but ethical concerns prohibited us from doing so. While the generic brand name (Kerrods), used to avoid breach of copyright, was intended to be neutral and has previously been found to have no positive or negative associations among smokers, ${ }^{7}$ it is nevertheless possible that this may have had an impact on participant's perceptions of plain packaging. The findings cannot be generalised to all young women smokers and provides no insight into the impact of plain packaging on older women smokers, male smokers or non-smokers, although the exclusive focus was on young women given the high smoking prevalence among this group. It is also possible that participants may respond differently if only plain packs were available on the legitimate market. Clearly, the true impacts of standardising the appearance of all legitimate cigarette packs on the market remain unclear. Research in Australia can help shed further light on the impacts of plain packaging. However, given that Australia has strong tobacco control, the largest on-pack warnings in the world and low prevalence of nicotine use, further research in Europe and elsewhere using approaches that more closely approximate what consumers experience while using plain packs in naturalistic settings is required.

\section{Implications for policy makers and clinicians}

As a number of governments consider the merits of plain packaging as a policy measure these findings may help inform the decision-making process. It is ultimately for policy makers to assess the potential value of plain packaging as part of a comprehensive suite of tobacco control measures aimed at reducing consumption and prevalence, but the collective evidence generally provides support for plain packaging, irrespective of design, location and sample. ${ }^{2}$ This study extends this growing body of evidence and is the first to find that smokers were more likely to stub out cigarettes early and reduce consumption while using plain packs. These findings are relevant to the National Institute for Health and Clinical Excellence draft guidelines on harm-reduction approaches to smoking, published in October 2012, ${ }^{19}$ which positions quitting as the target but points to potential health benefits of consuming fewer cigarettes, or less of each cigarette. Further research that provides greater insight into the impacts of plain packaging on smoking behaviour, and more broadly what the health benefits, if any, of reduced consumption and intake are, ${ }^{19}$ would be of value. However, the present findings contribute to the harm-reduction debate and suggest that plain packaging may have a role to play in this proposed harm-reduction approach.

The study also points to opportunities for clinicians. While plain packaging was found to increase thoughts of quitting, even while using their own packs between a quarter and a third of young women reported thinking about and wanting to quit. Smoking rates are higher for young women than for older women and for men of any age, ${ }^{5}$ and prevalence among 20 -year-olds to 24-year-olds has declined at a slower rate than it has for any other age group in the last quarter of a century, from $35 \%$ in 1984 to $30 \%$ in $2010 .{ }^{5}$ As such, the desire to change among a significant percentage of such a key target group suggests that young women may benefit from intervention by clinicians or healthcare professionals.

Acknowledgements The authors would like to thank Diane Dixon for her help with co-ordinating the study and data input, and Bedfont Scientific for providing piCO+ Carbon monoxide monitors.

Contributors CM designed data collection tools, monitored data collection, cleaned the data and drafted and revised the paper. CM is the guarantor. AMM designed data collection tools, analysed the data and drafted and revised the paper. All authors read and approved the final manuscript.

Funding This work was supported by Cancer Research UK grant number A13467. The funders had no role in study design; in the collection, analysis and interpretation of the data; in the writing of the report; and in the decision to submit the article for publication. The researchers are independent from the funders.

\section{Competing interests None.}

Ethics approval The study obtained ethics approval from the ethics committee of the Marketing Department at the University of Stirling. Participants provided informed consent before participating.

Provenance and peer review Not commissioned; externally peer reviewed.

Data sharing statement No additional data are available.

\section{REFERENCES}

1. Lee B. Sell tobacco in no-frills wrappers, urge doctors. Journal 1986;10:5.

2. Moodie C, Stead M, Bauld L, et al. Plain tobacco packaging: a systematic review. Stirling: Centre for Tobacco Control Research, University of Stirling, 2012.

3. Moodie C, Hastings GB, Mackintosh AM, et al. Young adult smokers' perceptions of plain packaging: a pilot naturalistic study. Tob Control 2011;20:367-73.

4. Eriksen M, Mackay J, Ross H. The tobacco atlas (4th Edition). Atlanta, Georgia: American Cancer Society, 2012.

5. The NHS Information Centre. Statistics on smoking: England, 2012. London: The Health and Social Care Information Centre, 2012.

6. Doxey J, Hammond D. Deadly in pink: the impact of female-oriented cigarette packaging among young women. Tob Control 2011;20:353-60. 
7. Moodie C, Ford A. Young adult smokers' perceptions of cigarette pack innovation, pack colour and plain packaging. Australas Mark $J$ 2011;19:174-80.

8. Carpenter CM, Wayne GF, Connolly GN. Designing cigarettes for women: new findings from the tobacco industry documents. Addiction 2005;100:837-51.

9. Heatherton TF, Kozlowski LT, Frecker RC, et al. The fagerstrom test for nicotine dependence: a revision of the fagerstrom tolerance questionnaire. Br J Addict 1991;86:1119-27.

10. Hegarty R. Do dark times lie ahead? The Grocer, 18 February 2012.

11. Wardle $\mathrm{H}$, Pickup $\mathrm{D}$, Lee $\mathrm{L}$, et al. Evaluating the impact of picture health warnings on cigarette packets. London: Public Health Research Consortium, 2012.

12. Moodie C, Ford A, Mackintosh AM, et al. Young people's perceptions of cigarette packaging and plain packaging: an online survey. Nic Tob Res 2012;14:98-105.

13. Centre for Tobacco Control Research. The packaging of tobacco products. Stirling: Centre for Tobacco Control Research, University of Stirling, 2012.
14. Munafo M, Roberts N, Bauld L, et al. Plain packaging increases visual attention to health warnings on cigarette packs in non-smokers and weekly smokers but not daily smokers. Addiction 2011:106:1505-10.

15. Maynard O, Munafó M, Leonards U. Visual attention to health warnings on plain tobacco packaging in adolescent smokers and non-smokers. Addiction 2013;108:413-19.

16. World Health Organisation. Elaboration of guidelines for implementation of Article 11 of the Convention. Third session of the Conference of the Parties to the WHO Framework Convention on Tobacco Control. Durban, South Africa, 17-22 November 2008. http:// www.who.int/fctc/guidelines/article_11.pdf (accessed 8 Sept 2012)

17. Department of Health. Consultation on standardised packaging of tobacco products: equality impact assessment. London: Department of Health, 2012.

18. Royal College of Physicians. Passive smoking and children. London Royal College of Physicians, 2010.

19. National Institute for Health and Clinical Excellence. Tobacco: harm-reduction approaches to smoking. London: NICE, 2012. 